\title{
DISCURSO DEL MAGISTRADO BARUCH DELGADO CARBAJAL, PRESIDENTE DEL TRIBUNAL SUPERIOR DE JUSTICIA Y DEL CONSEJO DE LA JUDICATURA DEL ESTADO DE MÉXICO, TOLUCA, 5 DE FEBRERO DE 2010
}

Con el permiso de este selecto auditorio, con el permiso de los señores consejeros que me acompañan, de los señores magistrados del Tribunal de lo Contencioso Administrativo y del Tribunal Superior de Justicia del Estado, de los señores diputados y de todos quienes integran la comunidad universitaria.

Agradezco al doctor Héctor Fix-Fierro y al maestro César Camacho Quiroz, la distinción que me fue conferida para participar en este importante evento académico.

Quiero aprovechar este foro, para reconocer la labor de investigación académica de quienes han participado en estos diez años para dar vida a esta revista especializada en el derecho constitucional, tan necesario para entender el origen, desarrollo y estructura del Estado.

Hablar de temas del máximo ordenamiento que estructura una nación, incluyendo la constitucionalidad local, es tarea de especialistas y profesionales de la investigación, que permiten el análisis de las instituciones jurídicas y políticas que se gestan en un Estado democrático y que impulsan el conocimiento y desarrollo del derecho constitucional.

La dogmatica del derecho constitucional en el devenir histórico ha buscado diversas alternativas que garanticen la observancia de las disposiciones constitucionales que rigen una nación, lo que ha generado el nacimiento de diversos sistemas de control constitucional.

De entre los diversos sistemas de control constitucional, se significa de manera particular, el control constitucional por órgano jurisdiccional, que está a cargo de un órgano judicial establecido al efecto o bien, a cargo 
de toda autoridad judicial en cumplimiento del principio de supremacía constituciona. ${ }^{1}$

En México, corresponde su ejercicio al Poder Judicial federal, al haberse establecido en jurisprudencia que se encuentra vigente un sistema de control constitucional concentrado, en el que los tribunales federales son los únicos facultados para considerar si una ley o un acto es violatorio de disposiciones constitucionales; 1 lo anterior, al haberse estimado que el artículo 133 constitucional no es fuente de facultades de control constitucional para las autoridades que ejercen funciones jurisdiccionales respecto actos ajenos, como son las leyes emanadas del Congreso, ni de sus propias actuaciones, que les permitan conocer la constitucionalidad de estos actos, al establecerse que este precepto debe ser interpretado a la luz del régimen previsto por la propia carta magna para este efecto. Conclusión que estimo debe ser objeto de una nueva reflexión constitucional, pues convencido estoy que debemos transitar a un control difuso de la constitucionalidad que permita fortalecer nuestro Estado de derecho y el federalismo judicial.

Es de destacarse que en un régimen jurídico estatal y democrático de Estado de derecho, resulta indispensable el análisis del control de la constitucionalidad, concepción que inicia tanto en la producción legislativa como en los actos de los órganos públicos, cuando éstos ajustan su actuación a los parámetros señalados desde la Constitución misma y tanto las autoridades como los funcionarios tienen en ella, su referencia jurídica más elevada.

Eduardo Pallares con acierto ha señalado que: "El control de la Constitución es el sistema establecido por la ley, la mayoría de las veces por los legisladores constituyentes para mantener incólume el orden constitucional y con él, el respeto debido a la ley fundamental de un país, así como a su exacto cumplimiento". ${ }^{2}$

Entre los diversos medios de control de la constitucionalidad contamos con las controversias constitucionales, las acciones de inconstitucionalidad y el juicio de amparo, entre otros medios, de no menor importancia.

1 Cfr. Las tesis con los rubros: "Control judicial de la Constitución. Es atribución exclusiva del Poder Judicial de la Federación" y "Control difuso de la constitucionalidad de normas generales. No lo autoriza el artículo 133 de la Constitución"

2 Pallares, Eduardo, diccionario teórico práctico del juicio de amparo, 2a. ed., México, Porrúa, 1970, p. 276. 
Se debe mencionar que el marcado individualismo del que participa el juicio de amparo, con motivo de que su procedencia es sólo a instancia del gobernado en lo particular y a los alcances de la sentencia que en él se dicta, en realidad, no se le puede considerar como un sistema de defensa directo de la constitucionalidad, sino únicamente como un medio de defensa del individuo frente al Estado, que se resuelve en defensa secundaria y eventual de la Constitución.

Por ello, no es dable concebirlo como un verdadero medio de control de la constitucionalidad en sentido estricto, en virtud de que este control queda subordinado a la condición de que resulte lesionado un gobernado y de que éste quiera que se repare en su persona el agravio cometido, por lo que no importa la lesión en sí a la ley suprema, sino sólo en cuanto se traduce en un daño al gobernado.

De esta circunstancia parece cobrar mayor peso la posición que pretende desde hace varios años, ampliar los efectos de los alcances de la sentencia de amparo, para consagrarse como un verdadero medio de control de la constitucionalidad.

En este contexto, se debe resaltar la importancia de contar con instrumento de difusión de estudios relativos a diversas cuestiones constitucionales, pues las reflexiones que se derivan de la investigación jurídica en el campo del derecho constitucional permitirán, sin duda, avances para fortalecer el Estado de derecho y fomentar el respeto a los derechos fundamentales del gobernado.

Del contenido de esta obra se advierte que todos los temas que se abordan, resultan interesantes para la reflexión de diversos tópicos constitucionales, destacando el ensayo desarrollado por el doctor Julio Gabriel Bustillos Ceja, investigador de tiempo completo del Instituto de Investigaciones Jurídicas de la UNAM, quien habla de la realidad de la justicia constitucional que se ha gestado en nuestro país en el siglo XXI y que se puede analizar a través de sus resoluciones.

Tema por demás significativo para el Estado de México, quien ha apostado en la justicia constitucional, un medio de defensa primario de la constitucionalidad local.

A la Sala Constitucional del Poder Judicial del Estado, instaurada a partir del 13 de octubre de 2004, le corresponde garantizar la supremacía y control de la Constitución local, la que tiene a su cargo resolver las diferencias que surgen entre los diversos entes del poder público estatal 
y municipal, así como de las acciones de inconstitucionalidad planteadas en contra de leyes, reglamentos estatales y municipales, bandos municipales o decretos de carácter general, por considerarse contrarios a la Constitución local.

De entre los asuntos que han sido del conocimiento de la Sala Constitucional del Estado y que ha motivado el planteamiento de una controversia constitucional ante nuestro más alto tribunal, particularmente ante la Segunda Sala y que se generó al inconformarse una de las partes en contra de una resolución que, valga la redundancia, resuelve una acción de inconstitucionalidad local, con satisfacción hemos podido advertir que al resolverse la controversia constitucional 73/2009, por nuestro más alto tribunal, se privilegian las instituciones estatales que conocen del control constitucional local como órganos terminales, lo que sin duda fortalece el esquema de los medios estatales de control constitucional local y, en consecuencia, fortalece el federalismo judicial.

En este sentido, coincidimos plenamente con el doctor Bustillos Ceja en el artículo que se publica en la edición que se comenta, cuando señala como una de las principales conclusiones de su ensayo: que el análisis de la realidad actual de la justicia constitucional local mexicana muestra señales sobre su eficiencia y eficacia, entendidas la primera como la prontitud en la emisión de las resoluciones de fondo y la segunda, como el logro, mediante éstas, de la preservación del orden constitucional en las entidades federativas.

Finalmente, me permito señalar que el centralismo generado por el juicio de amparo, ha reavivado dentro de las entidades federativas la convicción de retornar al modelo de la doble jurisdicción, establecido por la Constitución de 1824, que permitía la observancia real y a cabalidad del federalismo judicial.

Es menester resaltar que el modelo de la doble jurisdicción, consagrado en la Constitución federal, respecto de las controversias relacionadas con la aplicación de leyes locales y para el efecto de que la resolución de los tribunales locales sea definitiva y firme y no se someta a la revisión de una autoridad judicial federal, sólo será posible por medio de reformas constitucionales a los artículos 14, 107 y 116, que estarían limitando la procedencia del amparo directo y privilegiando la confianza en las autoridades locales. 
Al respecto, resultan importantes las conclusiones que se plasman en al Libro blanco de la reforma judicial, publicado por la Suprema Corte de Justicia de la Nación, donde ya se establece la reflexión para el foro jurídico nacional, en el sentido de limitar la procedencia del amparo directo, lo que viene a fortalecer el tan anhelado federalismo judicial.

La esencia federalista del Estado mexicano conlleva buscar alternativas para fortalecer la autonomía judicial de las entidades federativas, de ahí que sí cuentan con atribuciones para darse su gobierno dentro del esquema constitucional establecido, para expedir leyes internas, deben entonces contar con atribuciones para que en última instancia y en aplicación e interpretación de sus propias leyes, sus tribunales emitan la decisión definitiva y firme en los asuntos de competencia local.

Al respecto Emilio Rabasa comentaba, desde su época, "que habría que decidir entre el respeto a la autonomía de los Estados, renunciando a una garantía individual o mantener el derecho consagrado en la Constitución prescindiendo del sistema de gobierno", circunstancias que considero, pueden coexistir bajo un real federalismo judicial al que debemos transitar.

Queda evidenciada la trascendencia académica con la que cuenta esta revista dentro del foro jurídico nacional e internacional, de la que pudiéramos seguir hablando el resto de la tarde y a pesar de ello, el tiempo sería insuficiente; por lo que, independientemente de la opinión y comentarios que un servidor pueda hacer de la misma, la mejor perspectiva será la de todos ustedes, quienes desde su ámbito de responsabilidad e interés profesional, sin duda estarán motivados en fomentar y difundir el estudio del derecho constitucional mexicano.

Quiero aprovechar este momento, para tomarle la palabra al doctor Héctor Fix-Fierro, quien plantea la posibilidad de publicar en conjunto con los tribunales locales, una revista que sea el foro de análisis y de reflexión de todos, quienes trabajamos en distintos ámbitos de competencia, en la jurisdicción local. Gracias doctor. 